\title{
Classification and selection methodology for temporary support systems for underground structures
}

\author{
Manoj Kumar and Jitendra Prasad \\ Steel Authority of India Limited \\ Jharkhand, India \\ manojgeologist84@gmail.com
}

\author{
AK Naithani \\ National Institute of Rock Mechanics \\ Bangalore, India
}

\begin{abstract}
In this paper a new methodology for evaluation and classification of support system that can be applied to rock tunneling is discussed. It is of great importance to consider long-term stability of rock mass around the openings of underground structure, during design, construction and operation. Varying geological conditions can lead to complications with respect to any underground excavations. The support system may be designed based on empirical, analytical and numerical methods. The support should be installed immediately after the excavation, delayed causes deformation. In this context, many temporary support techniques are chosen to perform as pre-support that can be installed during the first face of excavation around of underground openings. Temporary support used before the excavation for poor rock mass quality to increase the stand-up time by making generally an arch. These supports can also be installed during the excavation and in this paper Arch Method is discussed. Three types of techniques are used in arch method viz. forepoles, grouted arch \& spiles. This method is highly recommended and proven system that can be installed within tunnel excavation.
\end{abstract}

Keywords-weak rock mass; pre-support system; arch support methods.

\section{INTRODUCTION}

Weak rock masses encountered during the underground excavation are special challenges because they can lead to sudden and uncontrolled collapses unless appropriate action is taken timely [1]. The poor rock mass conditions leads a problem of instability for tunnel and face if the ratio of rock mass strength to in situ stress falls below 0.2 [2]. The stability may be enhanced through load transfer by the interaction of immediate support and surrounding ground conditions [3]. In order to control this type of behavior, temporary support is required additionally and ingenious means which does not allow uncontrolled deformation of underground and prevent the failure of ground. Different supports term as pre-support [4] pre-confinement [5] and pre-improvement [6], are initial utilized for tunnel construction when there is a requirement for support ahead of the tunnel face.

Researchers and designers used the pre-support techniques for underground excavation and these are divided into two fundamental techniques: (i) support employed in surrounding area of the crown above the face and (ii) face support. This study focuses on the pre-support in the surrounding area above the face at the crown of tunnel excavation or underground structure strictly during first phase of excavation. The different terminologies are used by researchers for the same support types as forepole $[7,8]$ pipe roofing $[9,10]$, and spile $[7,11]$. A comparison of support elements is given in Table -1 for two types of supports that exist in literature based on the work of Volkmann et al. [12] and Marinos [13]. In general terms, both authors define the support elements as a forepole and spiles respectively.

In this paper general terms are accepted for temporary support arrangement as Arch methods. The cited terminologies of arch methods are not deal with their practices and functional differences. However, these techniques or terminologies are defined in literatures, resulting in inconsistent approaches used by practitioners [14]. Therefore, a standardized classification of pre-support types is needed to facilitate and ensure that design engineers and practitioners communicate effectively and strictly to an established standard. Here these techniques and subtechniques are presented as a standardized classification for these pre-support types. The optimization use of support elements without established classification or clear definition is very typical [6].

Kate et al. [6] used varying diameter of the tunnel (10-30 $\mathrm{m})$ and the length of support elements $(6-18 \mathrm{~m})$ for analysis. However, author's does not address the condition of a support length (L) which is less than the height of the tunnel excavation (He). Because of poor selection methodology and in inappropriate installation techniques, generally support is not get success (Table 1). In order to preventing the failure of underground opening, or in order to minimize surface settlements longer support is normally used. For maintaining and enhancing the underground stability the standardized nomenclature is required for temporary support system with concern to utilize proper support elements.

\section{ARCH SUPPORT METHODS}

Arch support methods and its techniques are very conventional and economical in tunnel excavation, and are being used to increase the excavation front sustainability, 
minimize the land subsidence, and prevent debris rocks falling into the tunnel [15]. The geological conditions and the stability of the rock mass in which a tunnel or cavern is to be excavated are probably the greatest sources of risk in a project involving underground construction. In the absence of a reliable geological model the project can go seriously wrong [8]. Many researchers and practitioners have described the arch methods as Umbrella Arch Methods (UAM) $[1,7,16,17,18,19]$. The arch support or umbrella support can be discussed in to three categories based on different support elements and their application. These support elements are having different physical properties in order to installation.

TABLE I. INCONSISTENT NOMENCLATURE OF SUPPORT ELEMENTS OF ARCH METHOD

\begin{tabular}{|c|c|c|}
\hline & $\begin{array}{c}\text { Typical reference } \\
\text { excavation type: metro } \\
\text { tunnel }(\mathrm{He}=* 6.87 \mathrm{~m})[17]\end{array}$ & $\begin{array}{c}\text { Typical reference } \\
\text { excavation type: } \\
\text { highway tunnel }(\mathrm{He}= \\
* 8.85-* 14 \mathrm{~m})[33]\end{array}$ \\
\hline $\mathrm{L}<\mathrm{H}_{\mathrm{e}}$ & Forepole & Spiles \\
\hline Length & 3-4 m (sometimes $5 \mathrm{~m})$ & $\begin{array}{c}3-6 \mathrm{~m} \text { (12 } \mathrm{m} \text { if grout } \\
\text { injected })\end{array}$ \\
\hline Angle & $5^{0}-10^{0}$ & $5^{0}-15^{0}$ \\
\hline Overlap & $\begin{array}{c}1 / 4-3 / 4 \text { of length (generally } \\
1 / 2 \text { ) }\end{array}$ & $0.8-1.2 \mathrm{~m}$ \\
\hline Spacing & No reference & $\operatorname{Max} 30 \mathrm{~cm}$ \\
\hline Size & $32-38.1 \mathrm{~mm}$ & $25-28 \mathrm{~mm}$ \\
\hline $\mathrm{L}>\mathrm{H}_{\mathrm{e}}$ & Umbrella arch & Pipe umbrella \\
\hline Length & $9-16 \mathrm{~m}$ & $15-30 \mathrm{~m}$ \\
\hline Angle & $6^{0}-8^{0}$ & $-5^{0}$ \\
\hline Overlap & $\begin{array}{c}1 / 4-3 / 4 \text { of length (generally } \\
1 / 2 \text { ) }\end{array}$ & $\min 3 m$ \\
\hline Thickness & $* 3.65 \mathrm{~mm}$ & $8-25 \mathrm{~mm}$ \\
\hline Spacing & $* 30 \mathrm{~cm}$ & $30-50 \mathrm{~cm}$ \\
\hline Size & $114 \mathrm{~mm}$ & $76-200 \mathrm{~mm}$ \\
\hline \multicolumn{3}{|c|}{$\begin{array}{l}\mathrm{H}_{\mathrm{e}} \text {-height of excavation } \\
* \text { Not generalized values, }\end{array}$} \\
\hline
\end{tabular}

These categories are spiles, forepoles and grouted. The spiles is consist of metallic longitudinal elements which shorter than the height of the tunnel. The forepoles also consist of metallic longitudinal elements which are longer than height of tunnel. The grouted element consists of grout materials (i.e. combination of cement and aggregate). The difference between these categories (spiles, forepoles and grouted) are vary in respective of solidity, expenditure, and time commitment for installation if used within their applicable ranges $[12,20]$.

\section{A. Spiles}

Spiles are generally used as a fast and efficient temporary pre-support system for the working area in underground structures. Spiles may ensure the stability of open span of tunnel. Spiles are categorized as longitudinal support elements which less than the height of tunnel. Spiles can be installed in order to control the possible failure in underground structures when it is geological controlled [18].
Trinh et al. [21] suggested the installation methodology of spiles that it may be inserted at a range of angles of $5^{\circ}-40^{\circ}$ to the horizontal plane of the longitudinal axis of underground opening excavation and with $30 \mathrm{~cm}$ spacing center to center in order to accomplish adequate structural control and appropriate embedment. The standard size of spiles is normally diameter ranges from 25 to $50.8 \mathrm{~mm}$ and even $101.6 \mathrm{~mm}$ have also been used in large dimension of excavation. Spacing of spiles used during the installation is critical factor for controlling the large wedge type failures from falling between the individual support elements [22]. In order to install spiles terminology such as confined, double, continuous, and open grouted were used by Tuncdemir et al. [23] for the further categorization of arch support methods (Fig. 1). The authors have given different nomenclature based on installation system and support elements. These nomenclatures are i) spiles grouted arch, ii) spiles confined arch, iii) spiles continuous grout arch. These pre support categories related spiles are successfully used in underground projects. Spiles confined arch as temporary support was successfully used in Buon Kuop hydropower project in Vietnam for safely further excavation progress which hindered by a cave formed about $60 \mathrm{~m}$ above excavation due to $15-20 \mathrm{~m}$ weakness zone intersected during excavation of twin tunnel (fig. 2 and 3) [24].

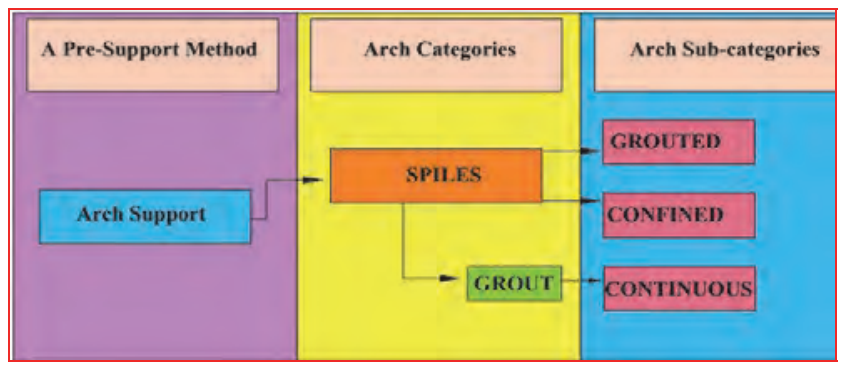

Fig. 1. Nomenclature of subcategories of arch method- Spiles

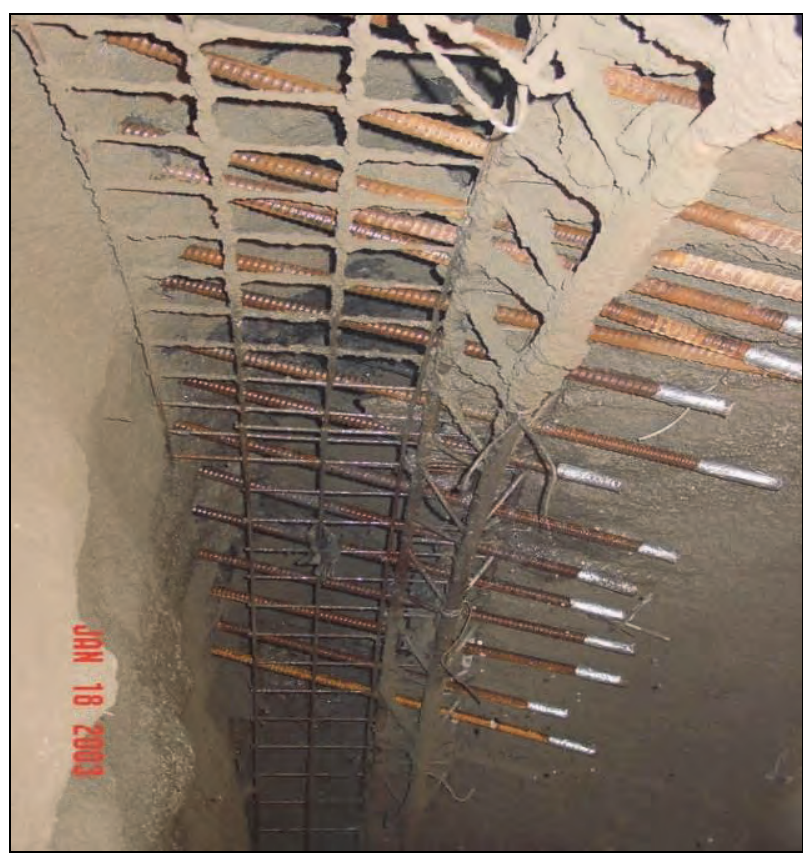

Fig. 2. Spiles installed in Buon Kuop hydropower project 


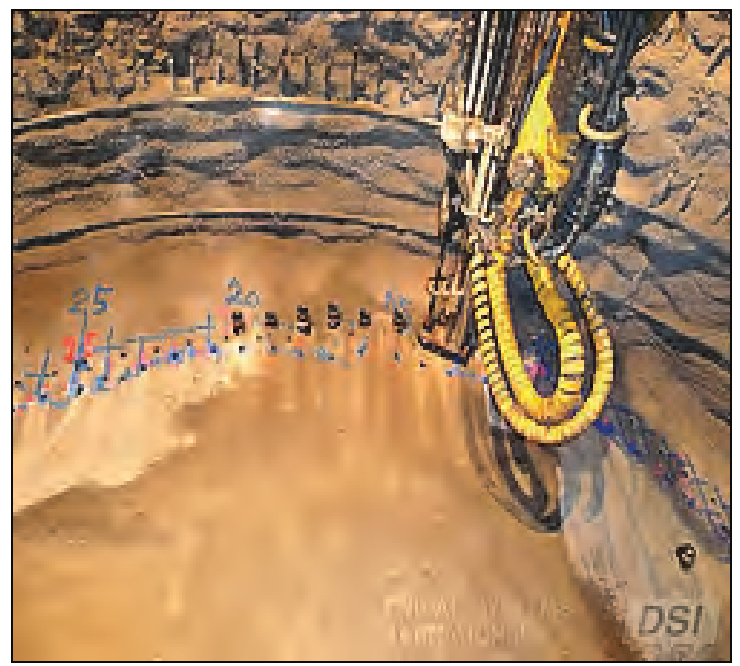

Fig. 3. Spiles installing at crown area

\section{B. Forepoles:}

Forepoles are temporary support elements which employed mostly in tunneling projects with very weak rock mass. When a large portion of weak rock mass or adverse geological conditions encountered during excavation and leads to possible failure, forepoles temporary support can be installed. Generally, they are used ahead of the face combination with other temporary support and build the stabilization zone surrounding the installed area in tunnel. Forepolling is safely temporary support which contributes to reducing the minimum support pressure in order to excavate the large dimension of tunnel under poor condition [25]. According to Warner [25] forepolling should be densely installed to reduce the influences from stress release at face and the crown. Face bolts only contributed to stress release at the face. Forepolling divide the surrounding ground of installed area into two zones; i) outside zone of invisible arch consisting of forepoles and ii) inside zone of the forepoles.

By definition, forepoles have a large diameter than spiles and their lengths are greater than the height of excavation [23]. The length of forepoles exceeds the ensuing plastic region around and ahead of the face within these weak rock regions [26]. The forepoles may be installed in shallow angle from the horizontal in longitudinal direction of tunnel alignment. The ideal condition of angle may from $3^{\circ}$ to $8^{\circ}$ with spacing range within $30-60 \mathrm{~cm}$ center to center. The spacing is based on the requirement to create the arching effect means overlapping of forepoles. The arching effect of forepoles is also defined by the size of the forepoles, which have an outside diameter of $60-168.3 \mathrm{~mm}$ and a wall thickness of 5-10 mm [23]. Different nomenclatures are described based on installation system and support elements. These nomenclatures are i) forepoles grouted arch, ii) forepoles confined arch, iii) forepoles double grouted arch, iv) forepoles double continuous grouted arch, v) forepoles continuous grouted arch, vi) forepoles open grouted are shown in fig. 4 . These all temporary support categories related to forepoles are successfully employed in several projects of the world.

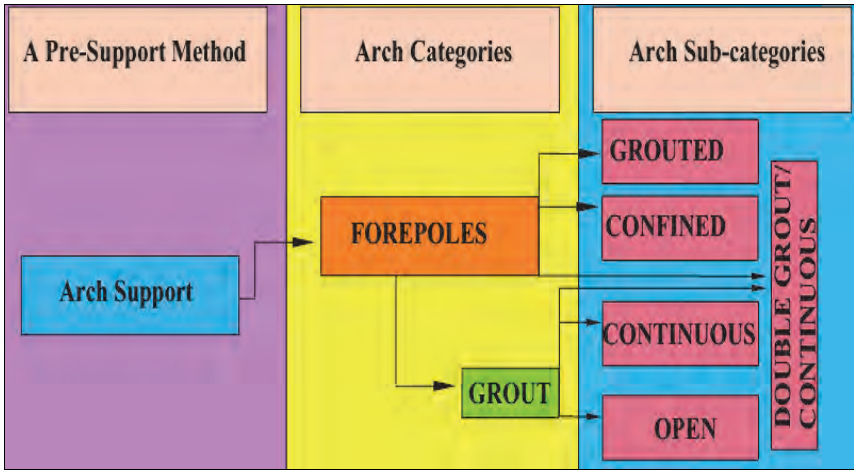

Fig. 4. Nomenclature of subcategories of arch method- Forepoles

A $400 \mathrm{~m}$ wide Daj Khad fault zone had encountered in Head Race Tunnel (HRT) of Nathpa Jhakri Hydro Electric Project (fig. 5) [8]. This zone was anticipated by site geologist/experts and also predicted in geological model. However, lithology of rock mass of this particular zone was not well characterized. Engineers and designers decided to handle this situation by using conventional steel set support for further safely excavation. But Steel support was not able to stabilize the fault zone. Afterword $12 \mathrm{~m}$ long grouted pipe forepoles were recommended by experts/engineers for stabilization of tunnel face (fig. 6 \&7). This method was highly successful and considered to be most appropriate approach for this type of situation.

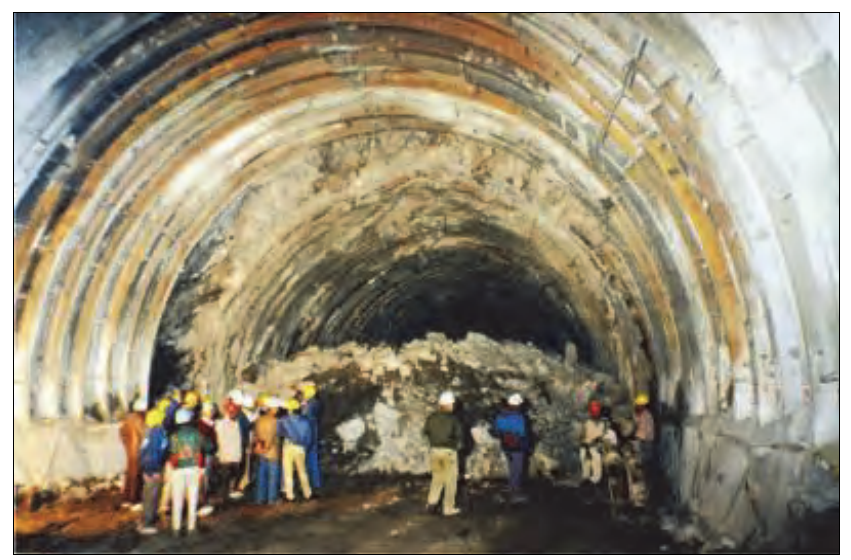

Fig. 5. Daj Khad fault zone encountered in HRT in at Nathpa Jhakri after Hoek [5]

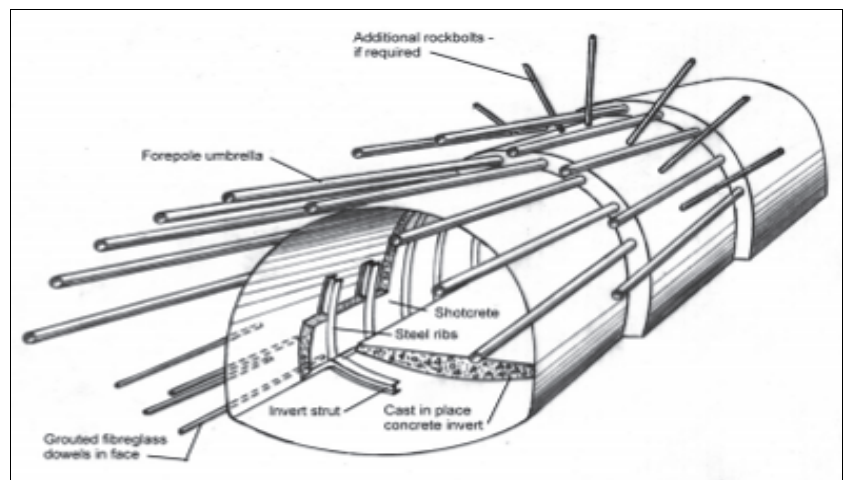

Fig. 6. Forepole Arch Method used in HRT at Nathpa Jhakri after Hoek [5] 


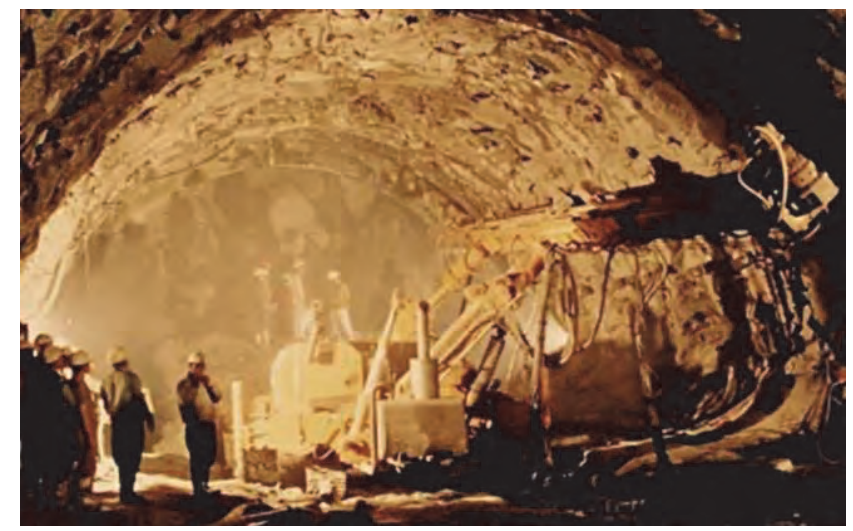

Fig. 7. Excavation through the Daj Khad Fault Zone using forepole Arch Method after Hoek [5]

\section{Grout}

The water seepage in underground structures is concerned for stability. The Grouting technique is generally utilized in underground projects as preventive measure to control the water seepage. This pre-support is used to provide the strength to rock strata. Grouting was first time introduced in the $1800 \mathrm{~s}$ as a reducing water leakage or decreasing permeability of rock mass.

Grouting is supportive techniques specially in filling the fissures \& cracks, and installing the forepolling, spiles, anchors [27]. Below the sea level the geological conditions of underground projects are quite difficult to perfectly explore because of the close proximity of an infinite amount of water seepage. Therefore subsea tunnels are significantly affected by the geological uncertainties and are more risky than most other tunneling projects [28]. This study is concerned only for grouting of arch method category which used independently in underground projects as a temporary support. Grouting is a pre reinforcement techniques used in underground excavation to protect the water seepage and enhance the stability and this is worldwide proven technology for enhance the stability if more fractures and crakes in rock mass occurred. Grouting is successfully used in crude oil storage cavern project to increase the stability caused by water seepage encountered during excavation (Fig. 8 \& 9) [26]. The Grouting installation procedure is similar like as installation of spiles and forepoles in terms of angle and overlap. Grouting spacing is based on permissible grouting pressure and as well as geological conditions of rock mass.

Each grouted support element is installed independently but it provides two types of arch structures 1) continuous arch if grouted support elements connected to each adjacent elements and 2) open arch structure if grouted support elements installed with having significant space

Engineers and experts have introduced various methods of grouting for tunneling and civil projects. Various methods with respect to the jet-grouting (mixing) system are given in Table 2 [27]. Jet grouting was successfully used for enhance the compressive strength of silt, sand, and gravel to a maximum of 5,10 , and $25 \mathrm{MPa}$ respectively.

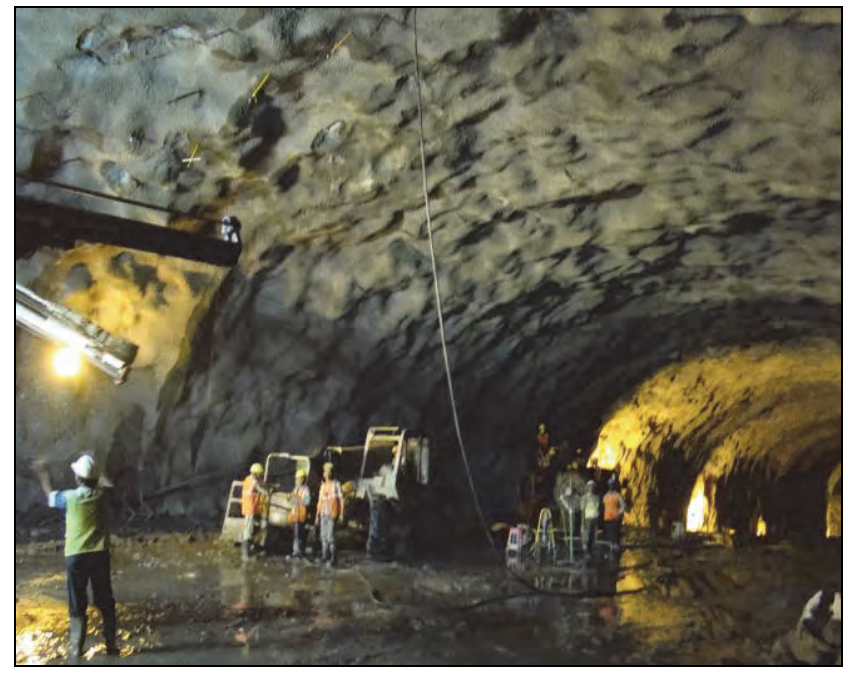

Fig. 8. Grouting in arch section of underground cavern project

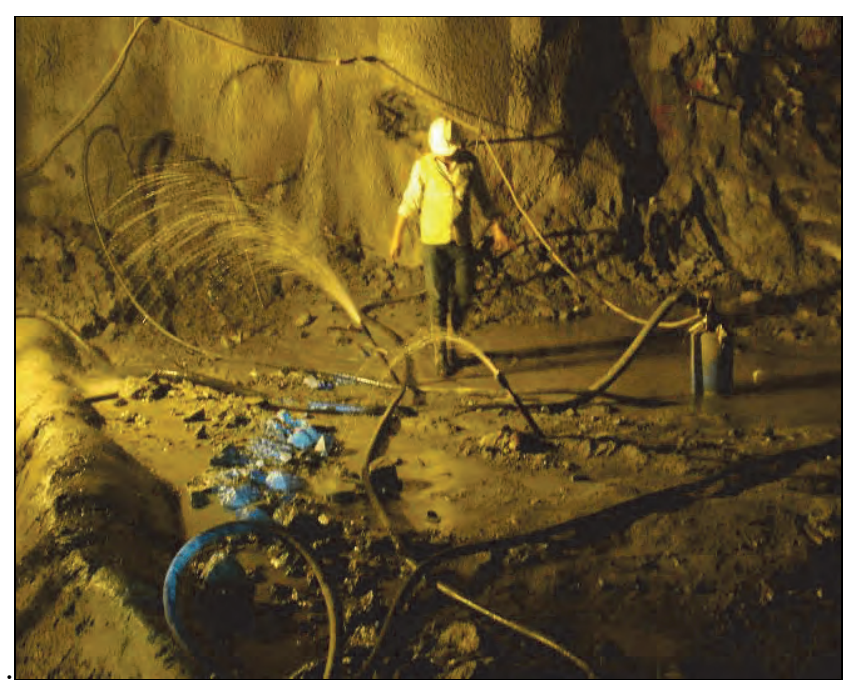

Fig. 9. Grouting in bottom area section of $\mathrm{u} / \mathrm{g}$ cavern project

\section{SELECTION METhodology OF TEMPORARY SUPPORT- ARCH METHODS FOR UNDERGROUND STRUCTURES}

As mentioned earlier that significant information is not available regarding temporary support in respect of terminology and their specific features like support elements. Due to this, selection of temporary support is very challenging. Oke et al. [14] have given the some guidelines for the selection of methodology for temporary support using arch method (fig. 10). In this figure authors illustrate the design for the Umbrella Arch Methods or pre-support techniques in response to indications of difficult regions that require pre-support.

The selection methodology of temporary support or arch system is based on design parameters to be considered and related to excavation such geological conditions, structural features, subsidence and water seepage. The support selection methodology for pre-support techniques or arch method are identified based on requirement of pre-support, behavior of excavated rock mass, geological or geotechnical conditions and preference of pre-support. 
TABLE II. Jet GROUting System [14, 27]

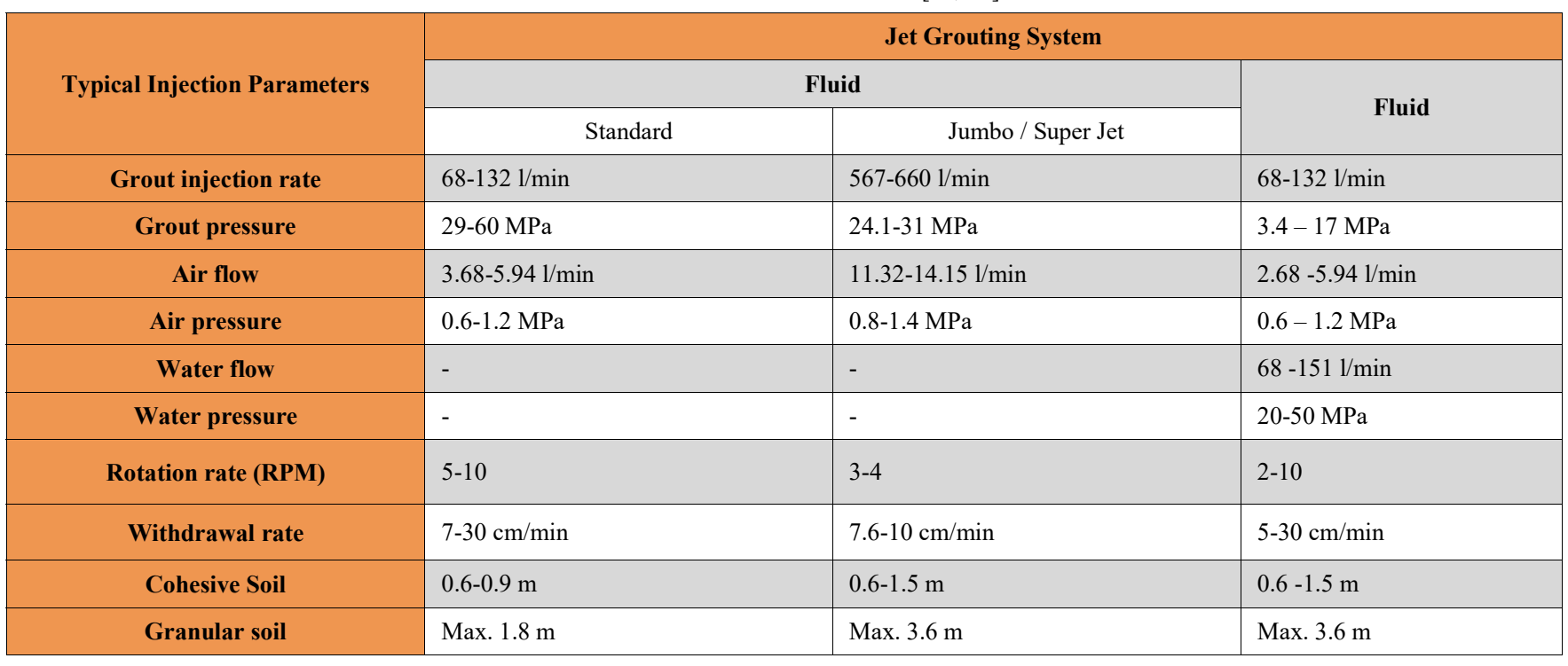

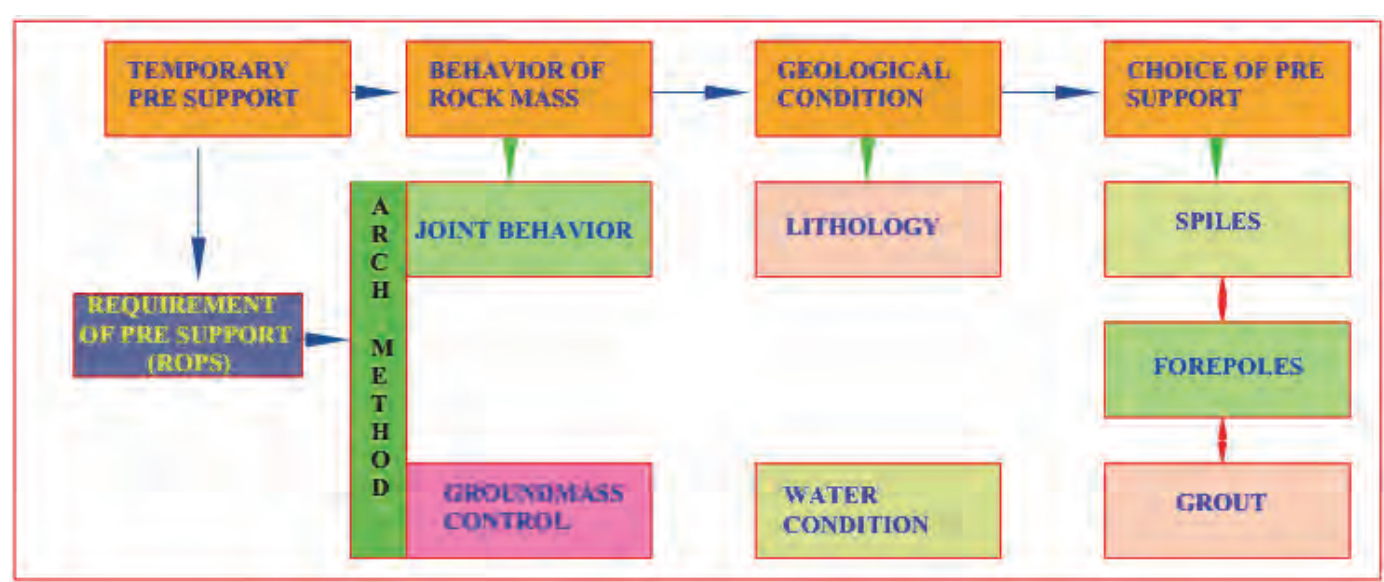

Fig 10 Schematic diagram for the selection of methodology of pre-support or arch methods

\section{A. Methodology 1: Requirement of Pre-support}

This methodology is totally based on the designer/geologist personal experience. Their experience can be used for adopting the selection procedures for presupport. In this methodology the design practice generally considers the two important aspects 1) an analysis and 2) an assessment pertaining to whether pre-support is required or not at the face profile for the unexcavated underground structures.

The analysis of cavern stability in second bench excavation of Padur underground crude oil storage cavern after using the software and based on experience, presupport techniques (forepoles and grouting) were employed for control the deformation in rock mass and further safely excavation [29]. In order to maintain the underground stability in difficult rock mass terrain pre-support techniques are successfully used in many projects by Designers based on their appropriate assessment.

\section{B. Methodology 2: Behavior of Excavated Rock Mass:}

Behavior of excavated rock mass is second and important methodology used for selection of pre-support techniques. In this methodology, the inclusion of a presupport is based on the improvement procedures which required countering the predictable behavior of rock mass affected by tunnel excavation. The influence of the joint orientation, depth and damage of the excavations and effects of the ground conditions are taken into consideration. The appropriate information regarding this methodology should have been previously investigated for selection of the excavation method. Hence, the Engineers have to decide as to pre-investigated ground behavior condition with methods for enhancing the stability. In order to understand this methodology the following subcategories have been proposed based on joint behavior and ground mass control.

The rock mass characterizations as intact, blocky, very blocky, blocky/disturbed/seamy, disintegrated, sheared/ foliated/laminated are well known and can provide a good description for rock mass (Fig 11). Other descriptions, such as good, medium, or poor to very poor, are very general and are not adequate for the purpose of identifying a behavior of rock mass [2 \& 13]. 


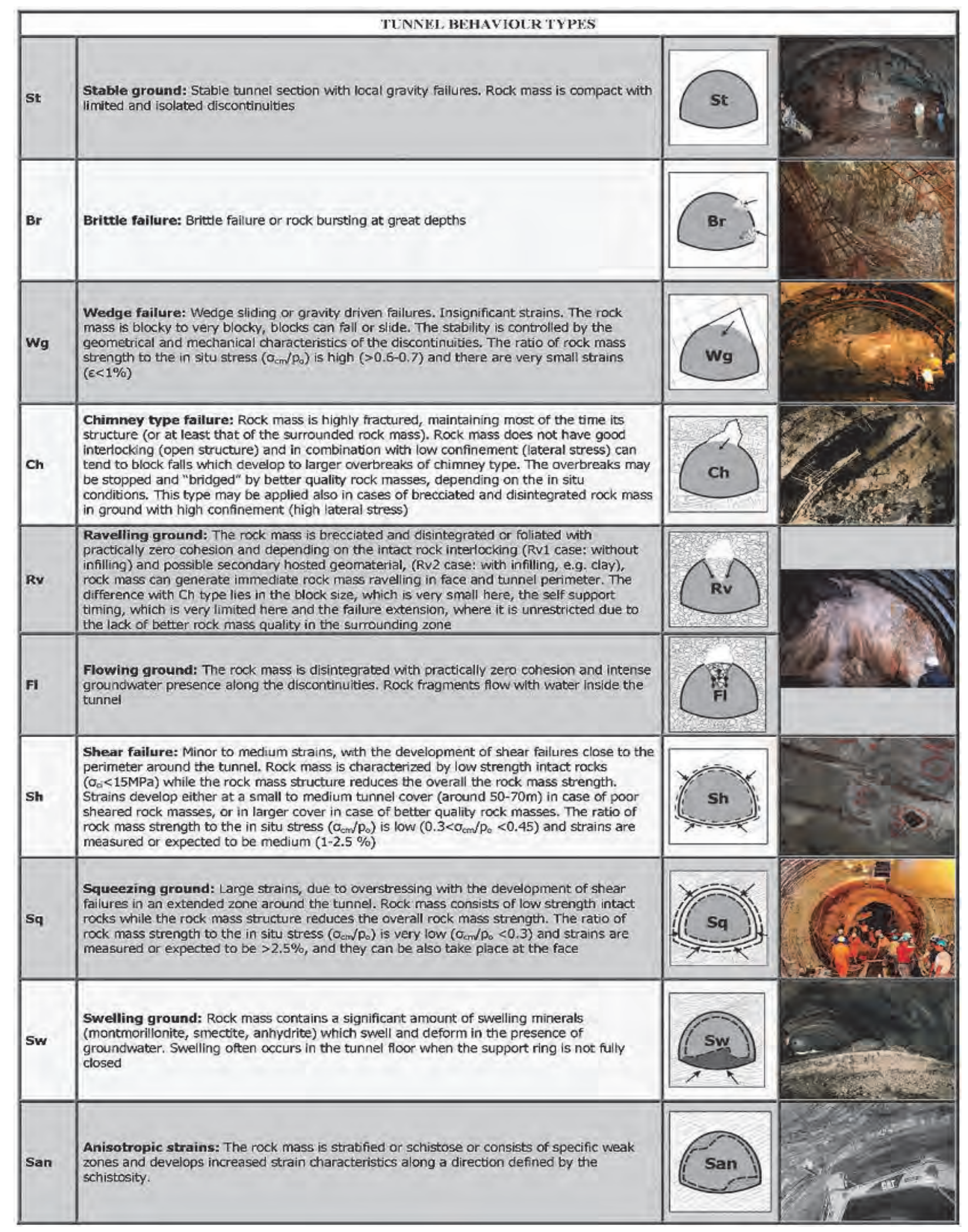

Fig. 11 Schematic diagram of tunnel behavior after Marinos [31]

\section{1) Joint Behavior}

The behavior of joints is having vital role in stability of any underground opening. The major structural features of underground opening may also be controlled by the block shape and size as well as their surface characteristics determined by the intersecting joints. The structural problems within the tunnel must be controlled in order to 
achieve safe excavation. The major failure occurs due to unfavorable behavior and orientation of joints. The arch method or pre-support can be installed in poor underground opening for safe excavation. The preliminary design require the discontinuity analysis and some form of geological modeling in order to aid in the definition of the anticipated structural failure. Hence, the support may be designed in terms of pre-support and installed exclusively as a safety precaution.

\section{2) Groundmass Control}

Underground excavation is a unique construction with full uncertainties and risk. Underground excavation will lead to various changes in the surrounding rocks in terms of deformation and stress distribution. Due to the vacuum generated within the mass element, a new balance of forces is established between its immediate surroundings, leading to a tunnel convergence that will inevitably be transmitted to the surface, creating the settlement trough. When undesirable convergence begins to occur due to the increase in gravity driven failures and/or increase stress conditions, this approach may be considered. If discontinuity failures or other forms of failure occur before the installation of the first support, an arch method needs to be employed. If any failure occurs due to any reasons during excavation, an arch method or their sub categories of pre-support needs to be employed to control the initial deformation, and to redistribute the stress conditions across other temporary supports.

\section{Methodology 3: Geological/Geotechnical Conditions}

The site investigations should be done to understand the geological/geotechnical conditions of the surroundings of any structures which lead to underground stability. The geological assessment plays a key role in planning, design and construction of underground structures facilities specially in adopting temporary support during the construction stage when poor rock mass encountered. During the construction stage the in situ stress confinement defines the geological conditions. The type of confinement either high or low will determine the temporary structural support elements such as spilles, forepoles and grout that will constitute the elements of the Arch Method. The impact of joint behavior and ground mass discussed in earlier section reflects the geological conditions. Two important factors are discussed for identifying the geological conditions to opt the temporary support methods.

\section{1). Lithology}

The lithology is a main constitute of geological investigations which indicates and influence of rock mass. The significant knowledge of formation of rock and subsequent of its type is supportive for selection of temporary support. Strength parameter of rocks depends on its formation, which provides the self-support/unsupport to underground structures. The permeability as physical property is high in sedimentary rock as compared to metamorphic rock. Generally properties of rock mass can be corresponded to the lithology of rock mass. Based on properties of rock mass, temporary support can be identified for further excavation leads to enhance the stability of tunnel opening.

\section{2) Water Conditions}

This constituent takes into account of water influence with respect to failure caused by lowering the water table or deterioration of rock surrounding the tunnel face. When the magnitude and radius of influence of water table is localized leads to induced deformations are often prone to generating large differential settlements and when influence of water table is widely spread the consequences are generally less severe [30]. Accordingly for the control of ingress of water into tunnel, support methods should be recommended.

\section{Methodology 4: Choice of Pre-support (Temporary support or Arch Methods)}

This method based on the choice of the suitable presupport elements of Arch Method. All three methodology discussed earlier are for the choice of appropriate support designed by the designer. All methodology and their sub methodology are much closed to requirements of temporary support needs to underground structures influenced by unfavorable rock mass strata. After getting full information about all methodology, designer and executing engineer can identify the temporary support of Arch Method as required based on site conditions.

\section{CONCLUSIONS}

The standardized nomenclature and selection methodology is proposed in this technical article. It may be helpful for the site engineer to choose the appropriate temporary support as per requirement. Extensive review on pre-support was done. The different pre-support elements viz. grout, spiles and forepoles and their sub categories employed at actual tunnel construction sites to improve the stability caused by unfavorable site conditions is discussed. The selection of methodology of Arch Methods is based on the collected site information on geological conditions, behavior of excavated rock mass with respect to stress conditions, joints behavior and presence of water at site.

\section{ACKNOWLEDGEMENTS}

Authors are thanks full to various researchers and practitioner whose work is referred here. The views expressed in the paper are of the authors and not relevant to any organization. First author express his gratitude to Management of RARE-2016 for sharing ideas to rock mechanics fraternity.

\section{REFERENCES}

[1] E. Hoek, "Support for very weak rock associated with faults and shear zones, International Symposium on Rock Support and Reinforcement Practice in Mining, Kalgoorlie, Australia," 14-19 March 1999, pp. 20.

[2] E. Hoek, and P. Marinos, "Predicting tunnel squeezing problems in weak heterogeneous rock masses," Tunnels and Tunnelling International, in press 2000.

[3] E. Hoek, "Big tunnels in bad rock," ASCE Journal of Geotechnical and Geo environmental Engineering, Sept 2001, Vol. 127, No. 9, pp. 726-740.

[4] S.H. Kim, S.H. Baek, and H.K. Moon, "A study on the reinforcement effect of umbrella arch method and prediction of tunnel crown and surface settlemen", In: Erdem Y, 
Solak T, editors. Underground space use: analysis of the past and lessons for the future. London: Taylor \& Francis; 2005. p. 245- 251.

[5] N. Vlachopoulos, and M.S. Diederichs, "Improved longitudinal displacement profiles for convergence confinement analysis of deep tunnels", International Journal of Rock Mechanics and Rock Engineering, 2009, vol. 42 no.2, pp.131-146.

[6] K. Date, R.J. Mair and K. Soga, "Reinforcing effects of forepoling and facebolts in tunneling Geotechnical Aspects of Underground Construction in Soft Ground - Ng”, Huang \& Liu (eds) (C) 2009 Taylor \& Francis Group, London, pp 635-641.

[7] G. Carrieri, P. Grasso, A. Mahtab, and S. Pelizza "Ten years of experience in the use of umbrella-arch for tunneling", Proceedings of the international congress on soil and rock improvement in underground works 1991, pp. 99-111.

[8] E. Hoek, "Alternative ground control strategies in underground construction", an International Symposium on Practices and Trends for Financing and Contracting Tunnels and Underground Works, Greece, on 22-23 March 2012

[9] W. L. Tan and P. G Ranjith, "Numerical Analysis of Pipe Roof Reinforcement in Soft Ground Tunneling", The 16th ASCE Engineering Mechanics Conference, University of Washington, Seattle, 16-18 July 2008.

[10]E. Hoek and E. T. Brown, "Practical Estimates of Rock Mass Strength", International Journal for rock Mechanic and mining Science, Dec. 1997, Vol. 34, issue 8, pp. 1165-1186.

[11]E. Hoek, "Tunnel support in weak rock", Keynote address, Symposium on sedimentary rock engineering, Taipei, Taiwan, 1998, pp20-22.

[12] G.M. Volkmann, W. Schubert, and E.A. Button, "A contribution to the design of tunnels supported by a pipe roof 50 Years of rock mechanics-Landmarks and future challenges", Proceedings of the 41st US symposium on rock mechanics, 2006 Golden, Colorado.

[13] V. Marinos, "Engineering geological behavior of rock masses in underground excavations" In Proceedings of the $11^{\text {th }}$ International congress of IAEG, 2010, Auckland, New Zealand.

[14] J. Oke, N. Vlachopoulos and V. Marinos, "Umbrella Arch Nomenclature and Selection Methodology for Temporary Support Systems for the Design and Construction of Tunnels" International Journal of Geotechnical and geological engineering, 2014, vol. 32 issue 1, pp. 97-130.

[15]A. Rostami, P. K. Dehkordi, M. A. Ziarati, S. Jahani, and K. Lotfi, "The Types of Tunnels Maintenance in Umbrella Arch Method", Open Journal of civil Engineering, Scientific Research Publishing, 2016, Vol 6, pp 156-162.

[16] G. M. Volkmann, and W. Schubert, "A contribution to the design of tunnels supported by a pipe roof", In Proceeding of 4th Asian Rock Mechanics Symposium, ISRM International Symposium, 2006, pp 8.

[17] S. Vardakos, "Back-analysis methods for optimal tunnel design", Dissertation, Blacksburg, Virginia: Virginia Polytechnic Institute and State University, 2007.

[18] G. Volkmann, "Rock mass-pipe roof support interaction measured by chain inclinometers at the Birgl tunnel" Proceedings of international symposium on geotechnical measurements and modeling, A.A. Balkema, Karlsruhe 2003, pp. 105-109.

[19]D. Peila, "Forepoling design Ground Improvement, Pre-support and Reinforcement Short Course", International Tunneling and Underground Space Association, WTC 2013, Geneva.

[20] G. Carrieri, P. Grasso, A. Mahtab, and S. Pelizza, "Ten years of experience in the use of umbrella-arch for tunneling", Proceedings SIG Conference On Soil and Rock Improvement, Milano, 1991, Vol.1, pp.99-111.

[21]Q.N. Trinh, E. Broch, and M. Lu, "Three dimensional modeling of spiling bolts for tunnelling at weakness zones" In: Eberhardt E, Stead D, Morrison T (eds) Rock mechanics: meeting society's challenges and demands, Taylar and Francis, 2007, London, pp 427-432.

[22]E. Hoek, "Practical rock engineering", Rocscience Inc, North Vancouver, 2007.

[23]H. Tuncdemir, C.O. Aksoy, E. Guclu, and S.C. Ozer, "Umbrella arch and forepoling support methods: a comparison", EUROCK, Stockholm, 2012, pp 515-527.
[24] P. Lunardi, "Design and construction of tunnels- analysis of controlled deformation in rocks and soils" (ADECO-RS) Springer, 2008, Berlin Heidelberg.

[25] J. Warner, "Practical handbook of grouting: Soil, Rock \& Structures", John Wiley \& Sons, lnc, 2004, New Jersey, pp. 720.

[26] M. Kumar, P. Jain, L.G. Singh and A. K. Naithani, "Rock support assessment for a unit-1 of underground strategic crude oil storage cavern project Padur, India”, In: Proceeding of National Seminar on Innovative Practices in Rock Mechanics, Bengaluru, 6-7 Feb 2014, pp. 94-102.

[27] J. Oke, N. Vlachopoulos, and M. Diederichs, "Sensitivity numerical analysis of orientations and sizes of Forepoles for underground excavations in weak rock" American Rock Mechanics Association, Chicago, 2012

[28] A. Palmström, "The challenge of subsea tunneling", Int. Jour. of Tunneling and Underground Space Technology, 1994, Vol. 9 No. 2.

[29] K. Song, G. Cho, Y. Sim, and I. Lee, "Optimization of a preimprovement support system for large underground excavation," Tunneling and Underground Space Technology, 2006, Vol.21, pp: 374.

[30]E. Leca, and N. Barry, "Settlements induced by tunneling in Soft Ground", Tunneling and Underground Space Technology, 2007, pp. 119-149. 